\title{
Three New Phenolic Amides from the Roots of Eggplant (Solanum melongena L.)
}

\author{
Teruhiko Yoshihara, Seiji Takamatsu and Sadao Sakamura \\ Department of Agricultural Chemistry, Faculty of Agriculture, \\ Hokkaido University, Sapporo 060, Japan
}

Received October 6, 1977

\begin{abstract}
The isolation of four phenolic amides, four phenolic compounds and an aromatic amine from the roots of eggplant is described. The phenolic amides were identified as $\mathrm{N}$-trans-feruloyl tyramine (V), N-trans-p-coumaroyl tyramine (VII), N-trans-feruloyl octopamine (VIII) and Ntrans-p-coumaroyl octopamine (IX). The three amides V, VIII and IX are new compounds. Furthermore, four phenolic compounds were identified as vanillin (I), isoscopoletin (II), ethyl caffeate (IV) and ferulic acid (VI). The aromatic amine was identified as $p$-aminobenzaldehyde (III).
\end{abstract}

It is generally recognized that some crops do not thrive when cropped annually on the same field. This phenomenon has been named "Iyachi" in Japanese and used to be avoided by rotating crops on the soil. In this connection, phytotoxic compounds originating from crops itself by excretion and decomposition of organic materials are regarded as one of the causual agents. In fact, it has been claimed by investigators that phenolic carboxylic acids in upland rice ${ }^{1)}$ and isoflavones in red clover ${ }^{2}$ ) act as the causual agent for affected crops. A typical example affected by continuous cropping can be seen in the plant family (Solanaceae) such as eggplant and tomatoes. Therefore, we first attempted to survey phenolic compounds in the roots of eggplant (Solanum melongena L.). This paper deals with the isolation and structure elucidation of four phenolic amides, four other phenolic compounds and an aromatic amine occurring in the roots of eggplant.

Fresh roots of eggplant were chopped and extracted with $70 \%$ ethanol. The extract was concentrated and the resulting aqueous solution was extracted with ether. The ether extract was concentrated and applied to a silica gel column. Eight fractions were obtained; three fractions (compound, $F_{1} \sim F_{3}$ ) from the eluent of chloroform and five fractions (compound, $F_{4} \sim F_{8}$ ) from the eluent of $5 \%$ methanol in chloroform. The $F_{6}$ compound shown to be a mixture of two polyphenols by means of paper chromatography was further chromatographed over a silica gel column and separated into two compounds referred to $F_{6 a}$ and $F_{6 b}$. All the compounds, except the $F_{3}$ compound, gave positive reactions to the phenol reagent.

The $F_{1}$ compound $(\mathrm{I}), \mathrm{M}^{+} 152$, was an aldehyde compounds, as evidenced by the positive reaction with 2,4-dinitrophenylhydrazine and identified as vanillin (I) by means of UV, PMR and IR. The $F_{2}$ compound (II) was yellow crystals, mp $185 \sim 187^{\circ} \mathrm{C}, \mathrm{M}^{+} 192$ and was considered to be isoscopoletin (II) by means of MS, UV. PMR and IR. Their identity was confirmed by comparison of these spectral data with those of the authentic specimens. ${ }^{3}$ ) The $\mathrm{F}_{3}$ compound (III), $\mathrm{C}_{7} \mathrm{H}_{7} \mathrm{NO}, \mathrm{M}^{+} 121$, melted at $98 \sim 100^{\circ} \mathrm{C}$ and gave positive reactions to the ninhydrin reagent and 2,4-dinitrophenylhydrazine, but not to the phenol reagent. In the IR spectrum of III, bands at 1603 and $780 \mathrm{~cm}^{-1}$ were attributed to an aromatic ring, bands at $1650 \mathrm{~cm}^{-1}$ to an aromatic amine group and bands at $1670 \mathrm{~cm}^{-1}$ to an aromatic aldehyde group. From these data, the structure of III was elucidated to be amino-benzaldehyde. In the PMR spectrum of III, the signals of a typical $p$-substituted benzene was observed; a doublet at $\delta 7.0$ and $7.85(J=9 \mathrm{~Hz})$ of each two aromatic protons. Thus, the $F_{3}$ compound 
was elucidated to be $p$-aminobenzaldehyde (III), which has not been isolated from any higher plant.

The $\mathrm{F}_{4}$ compound was obtained as crystals, mp $140 \sim 141^{\circ} \mathrm{C}, \mathrm{M}^{+} 208$, whose UV spectrum indicated the $\mathrm{F}_{4}$ compound to be one of the derivatives of caffeic acid. By means of MS, PMR and IR, the $F_{4}$ compound was identified as ethyl caffeate (IV). The ester IV seems to be an artifact formed from caffeic acid during the isolation procedure. The $F_{\mathrm{b}_{\mathrm{a}}}$ compound showed the UV spectrum similar to that of caffeic acid. The PMR spectrum revealed the presence of an aromatic methoxy group ( $\delta 3.92)$, and a mass spectrum showed $\mathrm{M}^{+}$ion peak at $m / e$ 194. From these data, the $\mathrm{F}_{\mathrm{Ba}}$ compound was elucidated to be ferulic acid (VI).

The $F_{6 \mathrm{~b}}$ compound (VII) obtained as crystals, mp $240 \sim 245^{\circ} \mathrm{C}$, showed $\lambda_{\max }$ at 294 and $312 \mathrm{~nm}$, indicating it to be a compound having a double bond conjugated to a benzene ring (e.g. p-coumaric acid, ferulic acid, caffeic acid etc.). Indeed, their IR spectra revealed the presence of an aromatic ring $\left(1605,1515 \mathrm{~cm}^{-1}\right)$ and trans-olefin $\left(980 \mathrm{~cm}^{-1}\right)$. In addition, VII had absorption bands of an amide group at $1670 \mathrm{~cm}^{-1}$ in the IR spectrum. The PMR spectrum of VII was evident for the existence of eight aromatic protons at $\delta 6.6 \sim 7.5$, an amine proton at $\delta 8.0$ and two trans-coupled vinylic protons at $\delta 6.4$ and $7.35(J=15 \mathrm{~Hz})$. An acetylated derivative (XI) of VII was prepared with acetic anhydride-pyridine, which gave a positive reaction to the Dragendorff reagent. This colour reaction suggested the $F_{60}$ compound to be an amide compound. The PMR spectrum of XI was evident for the existence of two acetyl groups $(\delta 2.3, \mathrm{~s}, 6 \mathrm{H})$. A mass spectrum of $\mathrm{XI}$ showed peaks at $m / e$ $367\left(\mathrm{M}^{+}\right), 147\left(\mathrm{HO}=\mathrm{CH}=\mathrm{CHCO}^{+}\right)$derived from acidic moiety and $120(\mathrm{HO}>\mathrm{CH}=$ $\mathrm{CH}_{2}{ }^{+}$) derived from amine moiety. From these data, the structure of the $F_{6 b}$ compound was assigned to $\mathrm{N}$-trans-p-coumaroyl tyramine (VIII), which had been isolated from the bark of Eyodia belahe B. ${ }^{4}$ The validity of the structure assignment was confirmed by com- parison of IR, MS, PMR and UV spectra with those of the synthetic specimen (XI) which was obtained from tyramine and acetyl $p$-coumaric acid.

The $F_{5}$ compound (V) obtained as syrup showed the IR and UV spectra similar to those of VII. The PMR spectrum of the $F_{5}$ compound showed signals similar to those of the $F_{6 b}$ compound except a peak assigned to a methoxy group $(\delta 3.8)$. The difference of 30 mass units of molecular ion peak between the $F_{5}$ compound $\left(M^{+} 313\right)$ and the $F_{6 b}$ compound $\left(\mathrm{M}^{+} 283\right)$ indicated the presence of a methoxy group on the phenolic moiety of the $F_{5}$ compound. The $F_{5}$ compound was therefore assigned as $\mathrm{N}$-trans-feruloyl tyramine (V). This. structure was also confirmed by synthesis.

The $F_{7}$ compound (VIII) and the $F_{8}$ compound (IX) showed the UV spectra similar to those of the $F_{5}$ and $F_{6 b}$ compounds. On acetylation, VIII and IX furnished the triacetyl derivative (XII and XIII, respectively), which gave a positive reaction to the Dragendorff reagent. The PMR spectrum of XII exhibited signals of $-\mathrm{CH}_{2} \mathrm{CH}-$ moiety at $\delta 3.7$ and 5.9 instead of those of $-\mathrm{CH}_{2} \mathrm{CH}_{2}-$ moiety at $\delta 2.9$ and 3.65 in XI. The methine signals of XII and XIII were observed at $\delta 5.9$ and 5.87 respectively, the functional groups in $-\mathrm{CH}$ - of $\mathrm{XII}$ and XIII being assigned as secondary alcohol. The PMR spectrum of XII was. evident for the existence of two acetyl $(\delta 2.3)$, one methoxy $(\delta 3.83)$, one amine $(\delta 5.7 \sim 6.1)$, one trans-olefinic $(\delta 6.26,7.53, J=16 \mathrm{~Hz})$ and seven aromatic protons $(\delta 6.9 \sim 7.4)$ other than $-\mathrm{CH}_{2} \stackrel{\mathrm{C}}{\mathrm{C}}-\mathrm{OAc}$ A mass spectrum of XII showed a molecular ion peak at $m / e 455$, and base peak at $m / e 177$ which corresponded to $\mathrm{H}_{3} \mathrm{CO}$

the mass of $\mathrm{HO}=\mathrm{CH}=\mathrm{CHCO}^{+}$. From these data, the structure of VIII was elucidated to be $\mathrm{N}$-trans-feruloyl octopamine. On the other hand, the PMR spectrum of XIII was. evident for the existence of two acetyl $(\delta 2.26)$, one methoxy $(\delta 3.7)$, two trans-olefinic $(\delta 6.25$, $7.54, J=15 \mathrm{~Hz})$ and eight aromatic protons $(\delta 6.9 \sim 7.5)$ other than $-\mathrm{CH}_{2}-\stackrel{\mathrm{C}}{\mathrm{C}} \mathrm{H}-\mathrm{OAc}$. A mass spectrum of XIII showed a molecular 
ion peak at $m / e 425$, and base peak at $m / e 147$ which corresponded to the mass of $\mathrm{HO}, \mathrm{CH}$ $=\mathrm{CHCO}^{+}$. From these data, the structure of IX was elucidated to be $\mathrm{N}$-trans-p-coumaroyl octopamine. The stereochemistry of octopamine in $F_{7}$ and $F_{8}$ compounds remains obscure.

The presence of amides of $p$-coumaric and ferulic acids in some plants has been reported previously; p-coumaroyl agmatine, ${ }^{\text {, }}$ feruloyl putrescine, ${ }^{6 /} p$-coumaroyl serotonin, ${ }^{7)}$ and feruloyl serotonin." However V, VIII and IX are new compounds which have never been previously encountered in nature.

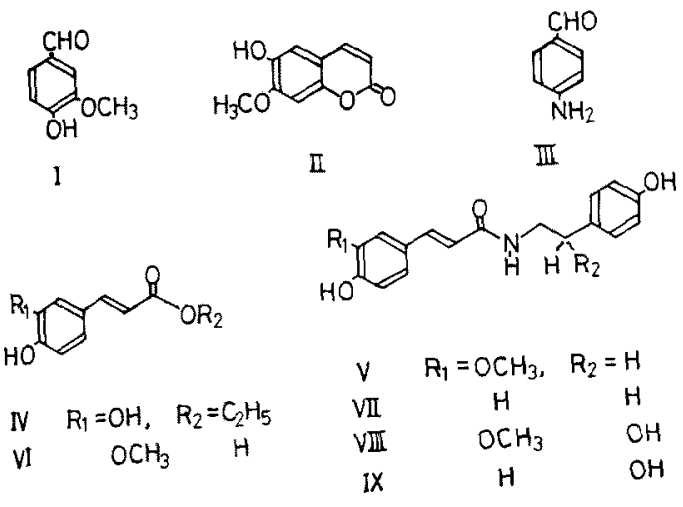

\section{EXPERIMENTAL}

Melting points were measured with an electrical apparatus (Yanagimoto MP 30) and uncorrected. Optical rotations were taken on Hitachi POB. UV spectra were recorded using HITACHI PERKINELMER 139 UV-VIS spectrophotometer. IR spectra were measured with HITACHI EPI-S2. Mass spectra were run on Hitachi RMU-7 in the direct way. PMR spectra were run on Hitachi R-22 (90Mc/sec).

\section{Isolation and separation}

The chopped fresh roots $(15 \mathrm{~kg})$ of eggplant were extracted with $70 \%$ EtOH. The filtrates were concentrated to approx. $400 \mathrm{ml}$ and then extracted with ether $(400 \mathrm{ml} \times 7)$. The ether extracts were concentrated under reduced pressure to a syrup $(15 \mathrm{~g})$, which was chromatographed over silica gel $(200 \mathrm{~g})$. The solvent system used was $4000 \mathrm{ml}$ of $\mathrm{CHCl}_{3}$ and $6000 \mathrm{ml}$ of $5 \%$ $\mathrm{MeOH}$ in $\mathrm{CHCl}_{3}$. The fractions collected were monitored by UV absorption at $280 \mathrm{~nm}$ and separated the eluate of $\mathrm{CHCl}_{3}$ into three fractions $\left(\mathrm{F}_{\mathrm{I}} \sim \mathrm{F}_{8}\right)$ and the eluate of $5 \% \mathrm{MeOH}$ in $\mathrm{CHCl}_{3}$ into five fractions $\left(\mathrm{F}_{4} \sim\right.$
$\left.F_{8}\right)$. The $F_{6}$ compound was further chromatographed over a silica gel column using $\mathrm{CHCl}_{2}-\mathrm{MeOH}-\mathrm{CH}_{3}$ $\mathrm{COOH}(100: 5: 5)$; and two compounds, referred to as $F_{6 s}$ and $F_{b b}$, in their order of elution were obtained.

\section{$F_{1}$ compound (vanillin, 1 )}

The $F_{I}$ compound was rechromatographed on a silica gel column with $50 \%$ ether in petroleum ether and resulted in pale yellow crystals of vanillin (I) from $\mathrm{CHCl}_{3}, 70 \mathrm{mg}\left(0.0005 \%\right.$ yield). UV $\lambda_{\max }^{\mathrm{EtOH}} \mathrm{nm}: 277$, 305 (sh). IR $\nu_{\max }^{\mathrm{KBr}} \mathrm{cm}^{-1}: 1700,1590,1290,870,830$. MS $m / e: 152\left(\mathrm{M}^{+}\right), 151(100 \%), 149,137,123,109,81$. PMR $\delta_{\mathrm{Me}_{4} \mathrm{Si}}^{\mathrm{CDCl}}: 4.0\left(3 \mathrm{H}, \mathrm{s},-\mathrm{OCH}_{3}\right), 6.45(1 \mathrm{H}, \mathrm{br},-\mathrm{OH})$, $6.9 \sim 7.5(3 \mathrm{H}, \mathrm{ArH}), 9.85(1 \mathrm{H}, \mathrm{s},-\mathrm{CHO})$.

\section{$F_{2}$ compound (isoscopoletin, II)}

The $F_{2}$ compound was rechromatographed on a silica gel column and resulted in yellow crystals of isoscopoletin (II) from $\mathrm{CHCl}_{3}, 140 \mathrm{mg}(0.001 \%$ yield), mp $185 \sim$ $187^{\circ} \mathrm{C}$. UV $\lambda_{\max }^{\mathrm{EtOH}} \mathrm{nm}: 299,346$. IR $\nu_{\max }^{\mathrm{KBx}} \mathrm{cm}^{-1}$ : 1700 (a-pyrone ring), 1600,1450 . MS m/e: $192\left(\mathrm{M}^{+}\right)$, $177,164,149(100 \%), 121,79,69,51$. PMR $\delta_{\mathrm{Me}_{4} \mathrm{Si}}^{\mathrm{CDCl}_{3}}$ : $3.95\left(3 \mathrm{H}, \mathrm{s},-\mathrm{OCH}_{3}\right), 6.12(1 \mathrm{H}, \mathrm{d}, J=10 \mathrm{~Hz},=\backslash), 6.74$ (1H, s, ArH), $7.12(1 \mathrm{H}, \mathrm{s}, \mathrm{ArH}), 7.77(1 \mathrm{H}, \mathrm{d}, J=10 \mathrm{~Hz}$, $\Rightarrow$ ).

\section{$F_{3}$ compound (p-aminobenzaldehyde, $I I I$ )}

The $F_{3}$ compound was rechromatographed on a silica gel column with $\mathrm{CHCl}_{8}-\mathrm{CH}_{3} \mathrm{COOC}_{2} \mathrm{H}_{5}$ (1:1) and resulted in white crystals of $p$-amino benzaldehyde (III) from $\mathrm{CHCl}_{3}, 70 \mathrm{mg}\left(0.0005 \%\right.$ yield), $\mathrm{mp} 98 \sim 100^{\circ} \mathrm{C}$. UV $\lambda_{\max }^{\mathrm{EtOH}} \mathrm{nm}(\varepsilon): 286(20,000)$. IR $\nu_{\max }^{\mathrm{K} \mathrm{EF}} \mathrm{cm}^{-1}: 1670$, $1650,1603,780$. MS $m / e: 122,121\left(\mathrm{M}^{+}, 100 \%\right), 93$, 65. PMR $\delta_{\mathrm{Me}_{4} \mathrm{Si}}^{\mathrm{CDC1}}: 6.6\left(2 \mathrm{H}, \mathrm{m},-\mathrm{NH}_{2}\right), 7.0(2 \mathrm{H}, \mathrm{d}, J=$ $9 \mathrm{~Hz}, \operatorname{ArH}), 7.85(2 \mathrm{H}, \mathrm{d}, J=9 \mathrm{~Hz}$. ArH $), 9.85(1 \mathrm{H}, \mathrm{s}$, $-\mathrm{CHO}$ ).

\section{$F_{4}$ compound (ethyl caffeate, IV)}

The $\mathrm{F}_{4}$ compound was rechromatographed on a silica gel column with $30 \%$ ethyl acetate in $\mathrm{CHCl}_{3}$ and resulted in crystals of ethyl trans-caffeate (IV) from $\mathrm{CHCl}_{3}, 95 \mathrm{mg}(0.0006 \%$ yield $), \mathrm{mp} 140 \sim 141^{\circ} \mathrm{C}$. UV $\lambda_{\max }^{\text {EtOH }} \mathrm{nm}(\varepsilon): 246,300(12,000), 331(16,000) . \quad$ IR $\nu_{\mathrm{mBr}}^{\mathrm{KBx}} \mathrm{cm}^{-1}: 1710,1270,970,870,810$. MS m/e: 208 $\left(\mathrm{M}^{+}\right), 180,163(100 \%), 145,136,117,89$, PMR $\delta_{\mathrm{Me}_{4} \mathrm{St}_{2}}^{\text {(CD }}: 1.27\left(3 \mathrm{H}, \mathrm{t}, \mathrm{CH}_{2}\right), 4.2\left(2 \mathrm{H}, \mathrm{q},-\mathrm{CH}_{2}\right), 6.2$ $(1 \mathrm{H}, \mathrm{d}, J=16 \mathrm{~Hz},=), 6.85(1 \mathrm{H}, \mathrm{d}, J=9 \mathrm{~Hz}, \mathrm{ArH}), 7.0$ $(1 \mathrm{H}, \mathrm{dd}, J=2 \mathrm{~Hz}, 9 \mathrm{~Hz}, \operatorname{ArH}), 7.12(1 \mathrm{H}, \mathrm{d}, J=2 \mathrm{H}$, ArH), $7.5(1 \mathrm{H}, \mathrm{d}, J=16 \mathrm{~Hz},=), 8.25(2 \mathrm{H}, \mathrm{br},-\mathrm{OH})$.

\section{$F_{82}$ compound (trans-ferulic acid, VI)}

The $F_{B a}$ compound was crystalized from $\mathrm{CHCl}_{3}$, and trans-ferulic acid (VI) was obtained as plates, $95 \mathrm{mg}(0.0006 \%$ yield $) \mathrm{mp} 152 \sim 156^{\circ} \mathrm{C}$. UV $\lambda_{\max }^{\mathrm{EtOH}} \mathrm{nm}$ (e): $294(11,700), 320(12,200) . \quad$ IR $\nu_{\mathrm{max}}^{\mathrm{K} \mathrm{Br}} \mathrm{cm}^{-1}: 1690$, 1600,970 . MS m/e: $194\left(\mathrm{M}^{+}, 100 \%\right), 179,150,135$. 
PMR $\delta \mathrm{Me}_{4} \mathrm{Mi}_{2} \mathrm{CO}: 3.92\left(3 \mathrm{H}, \mathrm{s},-\mathrm{OCH}_{3}\right), 6.35(1 \mathrm{H}, \mathrm{d}$, $J=15 \mathrm{~Hz},=\urcorner), 6.85(1 \mathrm{H}, \mathrm{d}, J=8 \mathrm{~Hz}, \mathrm{ArH}), 7.1(1 \mathrm{H}, \mathrm{dd}$, $J=2 \mathrm{~Hz}, 8 \mathrm{~Hz}, \mathrm{ArH}), 7.3(1 \mathrm{H}, \mathrm{d}, J=2 \mathrm{~Hz}, \mathrm{ArH}), 7.6$ $(\mathrm{IH}, \mathrm{d}, J=15 \mathrm{~Hz},=)$.

\section{$F_{5}$ compound (N-trans-feruloyl tyramine, $V$ )}

The $F_{\tilde{s}}$ fraction was evaporated to dryness under reduced pressure and rechromatographed on a silica gel column with $\mathrm{CHCl}_{3}-\left(\mathrm{CH}_{3}\right)_{2} \mathrm{CO}-\mathrm{CH}_{3} \mathrm{COOH}$ (40: $10: 1)$ and resulted in a syrup of $\mathrm{N}$-trants-feruloyl tyramine $(V), 60 \mathrm{mg}\left(0,0004 \%\right.$ yield). UV $\lambda_{\mathrm{max}}^{\mathrm{EtOH}} \mathrm{nm}(\varepsilon)$ : $290(10,700), 320(12,700) . \quad$ IR $\nu_{\max }^{\mathrm{film}} \mathrm{cm}^{-1}: 1705$, 1590, 1430, 970. MS m/e: 315, $313\left(\mathrm{M}^{+}\right), 194,193$, $192,177(100 \%), 149,145,120$. PMR $\hat{o}_{\mathrm{Me}_{4} \mathrm{Si}}^{(\mathrm{CD})_{2} \mathrm{CO}}: 2.75$ $\left(2 \mathrm{H}, \mathrm{m},-\mathrm{CH}_{2}\right), 3.45\left(2 \mathrm{H}, \mathrm{m},-\mathrm{CH}_{2}\right), 3.8\left(3 \mathrm{H}, \mathrm{s}_{\text {s }}\right.$ $\left.\left.-\mathrm{OCH}_{3}\right), 6.4(1 \mathrm{H}, \mathrm{d}, J=15 \mathrm{~Hz},=)\right), 6.6 \sim 7.2(7 \mathrm{H}, \mathrm{m}$, $\operatorname{ArH})_{2} 7.4(1 \mathrm{H}, \mathrm{d}, J=15 \mathrm{~Hz},=), 7.8(1 \mathrm{H}, \mathrm{d},>\mathrm{NH})$, $8.1(2 \mathrm{H}, \mathrm{m}, \mathrm{OH})$.

Acetylation of $F_{5}$ compound (V) (50 mg) with acetic anhydride and pyridine yielded diacetyl $\mathrm{N}$-feruloyl tyramine $(\mathrm{X})(40 \mathrm{mg}, 63 \%$ yield $)$ as syrup. UV $\lambda_{\max }^{\mathrm{EtOH}}$ $\mathrm{nm}(\varepsilon): 278(14,800)$. IR $\lambda_{\max }^{\text {thin }}$ film $\mathrm{cm}^{-1}: 3400,1760$, $1660,1610,1410,1220,970$. MS m/e: $397\left(\mathrm{M}^{+}\right)$, $355,192,177,149,120,107,43(100 \%)$. PMR $\delta_{\mathrm{Me}_{4} \mathrm{Si}_{3}}^{\mathrm{CHCl}_{3}}$ $2.34\left(6 \mathrm{H}, \mathrm{s}, \mathrm{CH}_{3} \mathrm{CO}-\mathrm{O}-\mathrm{Ar}\right), 2.84\left(2 \mathrm{H}, \mathrm{m},-\mathrm{CH}_{2}-\right.$, $3.6\left(2 \mathrm{H}, \mathrm{m},-\mathrm{CH}_{2}-\right), 3.85\left(3 \mathrm{H}, \mathrm{s},-\mathrm{OCH}_{3}\right), 5.85(1 \mathrm{H}, \mathrm{m}$, NH) $6.28(1 \mathrm{H}, \mathrm{d}, J=16 \mathrm{~Hz},=), 6.9 \sim 7.3(7 \mathrm{H}, \mathrm{Ar}-$ H), $7.56(1 \mathrm{H}, \mathrm{d}, J=16 \mathrm{~Hz},=)$.

\section{$F_{a b}$ compound (N-p-coumaroyl tyramine, VII)}

The $F_{B b}$ fraction was evaporated to dryness under reduced pressure and the residue was crystallized from $\mathrm{CHCl}_{3}$ to give $\mathrm{N}$-p-coumaroyl tyramine (VII) as powder $98 \mathrm{mg}\left(0.0006 \%\right.$ yield), mp $240 \sim 245^{\circ} \mathrm{C}$, Anal. Found: C, $71.44 ; \mathrm{H}, 6.14 ; \mathrm{N}, 4.98$. Caled. for $\mathrm{C}_{17} \mathrm{H}_{17} \mathrm{NO}_{3}$ : C, $72.08 ; \mathrm{H}, 6.01 ; \mathrm{N}, 4.95 \%$ UV $\lambda_{\max }^{\mathrm{EtOH}} \mathrm{nm}(\varepsilon): 294$ $(26,400), 312(26,000) . \quad$ IR $\nu_{\max }^{\mathrm{KR}} \mathrm{cm}^{-1}: 1670,1605$, $1515,980,830$. MS m/e: $284,283\left(\mathrm{M}^{+}\right), 164,147,119$, $107,91(100 \%)$. PMR $\delta_{\mathrm{Me}_{4} \mathrm{Si}}^{\mathrm{DSO}}: 6.4(1 \mathrm{H}, \mathrm{d}, J=15 \mathrm{~Hz}$, $==), 6.7(1 \mathrm{H}, \mathrm{d}, J=10 \mathrm{~Hz}, \mathrm{ArH}), 6.8(1 \mathrm{H}, \mathrm{d}, J=$ $10 \mathrm{~Hz}, \mathrm{ArH}), 7.02(1 \mathrm{H}, \mathrm{d}, J=10 \mathrm{~Hz}, \mathrm{ArH}), 7.4(1 \mathrm{H}, \mathrm{d}$, $J=10 \mathrm{~Hz}, \mathrm{ArH}), 7.35(1 \mathrm{H}, \mathrm{d}, J=15 \mathrm{~Hz},=y), 8.0(1 \mathrm{H}$, $\mathrm{m},>\mathrm{NH})$.

Acetylation of $F_{6 b}$ compound (VII) by the usual way gave diacetyl $N$-p-coumaroyl tyramine (XI) (45 mg, $77 \%$ yield), mp $160^{\circ} \mathrm{C}$ (from $\mathrm{CHCl}_{3}$ ). Anal. Found; $\mathrm{C}, 66.9 ; \mathrm{H}, 5.71 ; \mathrm{N}, 3.76$. Caled. for $\mathrm{C}_{21} \mathrm{H}_{2 \mathrm{~N}} \mathrm{NO}_{5}$ : C, $68.66 ; \mathrm{H}, 5.72 ; \mathrm{N}, 3.81 \%$. UV $\lambda_{\max }^{\mathrm{EtOH}} \mathrm{nm}(\varepsilon): 281$ (26,600). IR $\nu_{\max }^{\mathrm{KRr}} \mathrm{cm}^{-1}: 3300,1770,1680,1620,1220$, 970. MS mle: $367\left(\mathrm{M}^{+}\right), 325,283,206,189,162,147$ $(100 \%), 120,107,91$. PMR $\delta_{\mathrm{Me}_{4} \mathrm{SP}_{1}}^{\mathrm{CDC}}: 2.3\left(6 \mathrm{H}, \mathrm{s}, \mathrm{CH}_{3} \mathrm{CO}\right.$ -O-Ar), $2.9\left(2 \mathrm{H}, \mathrm{t}, J=6 \mathrm{~Hz}, 6 \mathrm{~Hz},-\mathrm{CH}_{2}\right), 3.65(2 \mathrm{H}, \mathrm{t}, J=$ $\left.6 \mathrm{~Hz}:-\mathrm{CH}_{2}-\right), 5.7(1 \mathrm{H}, \mathrm{m},>\mathrm{NH}), 6.78(1 \mathrm{H}, \mathrm{d}, J=15 \mathrm{~Hz}$, $=\mathrm{y}), 6.9 \sim 7.6(8 \mathrm{H}, \mathrm{m}, \mathrm{ArH}), 7.6(1 \mathrm{H}, \mathrm{d}, J=15 \mathrm{~Hz}$, $=y$.
$F_{7}$ compound ( $N$-trans-feruloyl octopamine, VIII)

Acetylation of $\mathrm{F}_{7}$ compound (VIII) $(60 \mathrm{mg})$ by the usual way gave triacetyl N-feruloyl octopamine (XII) (21 mg, 25\% yield), mp $155 \sim 157^{\circ} \mathrm{C}$ (from $\mathrm{CHCl}_{3}$ ), $[a]_{\mathrm{D}}^{22}-5.3(c=1.75, \mathrm{EtOH})$, UV $\lambda_{\max }^{\mathrm{EtOH}} \mathrm{nm}(s): 281$ $(17,000) . \quad$ IR $\nu_{\mathrm{max}}^{\mathrm{KR}} \mathrm{cm}^{-1}: 3300,1770,1660,1620$, 1410, 1210, 970. MS $m / e: 455\left(\mathrm{M}^{+}\right), 413,395,353$, $352,311,249,177(100 \%)$. PMR $\delta_{\mathrm{Me}_{4} \mathrm{~S}_{1}}^{\mathrm{CDCl}}: 2.13(3 \mathrm{H}, \mathrm{s}$, $\left.\mathrm{CH}_{3} \mathrm{CO}-\mathrm{O}-\mathrm{Ar}\right), 2.3\left(6 \mathrm{H}, \mathrm{s}, \mathrm{CH}_{3} \mathrm{CO}-\mathrm{O}-\mathrm{Ar}\right), 3.7(2 \mathrm{H}$, $\mathrm{m},-\mathrm{CH}_{2}-3.83\left(3 \mathrm{H}, \mathrm{s},-\mathrm{OCH}_{3}\right), 5.9(1 \mathrm{H}, \mathrm{m},-\mathrm{CH})$, $5.7 \sim 6.1(1 \mathrm{H}$, br, $\mathrm{NH}), 6.26(1 \mathrm{H}, \mathrm{d}, J=16 \mathrm{~Hz},=y)$, $6.5 \sim 7.4(7 \mathrm{H}, \mathrm{m}, \mathrm{ArH}), 7.53(1 \mathrm{H}, \mathrm{d}, J=16 \mathrm{~Hz},=\mathrm{v})$.

$F_{8}$ compound $(N-p$-coumaroyl octopamine, $I X)$

Acetylation of $F_{8}$ compound (IX) (11 mg) by the usual way gave triacetyl $\mathbf{N}$-p-coumaroyl octopamine (XIII) ( $8 \mathrm{mg}, 51 \%$ yield), $\mathrm{mp} 154 \sim 156^{\circ} \mathrm{C}$ (from $\mathrm{CHCl}_{3}$ ), $[a]_{\mathrm{D}}^{22}+8.0(c=2.75$, EtOH$)$. UV $\lambda_{\max }^{\operatorname{EtOH}} \mathrm{nm}(\varepsilon): 281$ (9800). IR $\nu_{\mathrm{max}}^{\mathrm{KBr}} \mathrm{cm}^{-1}: 3300,1760,1660,1620,1420$, 1210, 970. MS m/e: $425\left(\mathrm{M}^{+}\right), 365,323,281,219$, $189,177,147(100 \%), 135,119 . \quad$ PMR $\delta_{\mathrm{Me}_{4} \mathrm{Sl}}^{\mathrm{CDCl}}: 2.1$ ( $\left.3 \mathrm{H}, \mathrm{s}, \mathrm{CH}_{3} \mathrm{CO}-\mathrm{O}-\mathrm{Ar}\right), 2.26\left(6 \mathrm{H}, \mathrm{s}, \mathrm{CH}_{2} \mathrm{CO}-\mathrm{O}-\mathrm{Ar}\right)$, $3.7\left(2 \mathrm{H}, \mathrm{m},-\mathrm{CH}_{2}\right), 5.87(1 \mathrm{H}, \mathrm{m},-\mathrm{CH}), 6.25(1 \mathrm{H}, \mathrm{d}$, $J=15 \mathrm{~Hz},=), 6.9 \sim 7.5(8 \mathrm{H}, \mathrm{m}, \operatorname{ArH}), 7.54(\mathrm{HH}, \mathrm{d}$, $J=15 \mathrm{~Hz},=$ ).

Synthesis of the acetyl derivatives of the amides $(V, V I I$, VIII and $I X)$

a) Diacetyl $N$-feruloyl tyramine. To a solution of $593 \mathrm{mg}$ of O-acetyl ferulic acid $(2.5 \mathrm{mmole})$ and $0.5 \mathrm{ml}$ of triethylamine in $5 \mathrm{ml}$ of absolute tetrahydrofurane $0.25 \mathrm{ml}$ of ethylchlorocarbonate (2.6 mmole) was added, and allowed to stand for $1 \mathrm{hr}$. After that $456 \mathrm{mg}$ of tyramine hydrochloride $(2.5 \mathrm{mmole})$ and $0.5 \mathrm{ml}$ of triethylamine were added. The reaction mixture was stirred overnight at room temperature.

The mixture was evaporated to a solid, and dissolved in $2 \mathrm{ml}$ of acetic anhydride and $2 \mathrm{ml}$ of dry pyridine, which was allowed to stand overnight. The solution was evaporated to a solid, chromatographed over silica gel $(70 \mathrm{~g})$ with $2 \% \mathrm{MeOH}$ in $\mathrm{CHCl}_{3}$ and yielded diacetate of the amide ( $470 \mathrm{mg}, 47 \%$ yield) as white powder. This was identical with diacetate of natural $\mathrm{N}$-feruloyl tyramine in all respects.

b) Diacetyl $N$-p-coumaroyl tyramine. O-Acetyl $p$-coumaric acid $(82 \mathrm{mg}$ ) and tyramine hydrochloride (72 $\mathrm{mg}$ ) were treated as described above, and diacetyl $\mathrm{N}$-p-coumaroyl tyramine was obtained (360 mg, $41 \%$ yield).

c) Triacetyl N-feruloyl octopamine. O-Acetyl ferulic acid $(60 \mathrm{mg})$ and $d l$-octopamine hydrochloride $(60 \mathrm{mg})$ were treated as described above, and triacetyl $\mathrm{N}$-feruloyl $d l$-octopamine was obtained $(30 \mathrm{mg}, 26 \%$ yield).

d) Triacetyl N-p-coumaroyl octopamine. O-Acetyl $p$-coumaric acid (62 $\mathrm{mg}$ ) and dl-octopamine hydro- 
chloride $(72 \mathrm{mg}$ ) were treated as described above, and triacetyl $\mathrm{N}$-p-coumaroyl $d$-octopamine was obtained (170 mg, 75\% yield).

\section{REFERENCES}

1) K. Munakata and T. Yamada, Nogyo Oyobi Engei, 34, 1117 (1959).

(2) S. Tamura, C.-F. Chang, A. Suzuki and S. Kumai, Agric. Biol. Chem., 33, 391 (1969); C.-F. Chang, A. Suzuki, S. Kumai and S. Tamura, ibid., 33, 398 (1969),
3) F. Shafizadeh and A. B. Melnikoff, Phytochemistry, 9, 1311 (1970).

4) J. Rondest, B. C. Das and J. Polonsky, Bull. Soc. Chim. Fi., 1968, 2411.

5) A. Stoessl, Phytochemistry, 4, 973 (1965).

6) T. A. Wheaton and I. Stewart, Nature, 206, 620 (1965).

7) Y. Terayama, A. Ichihara and S. Sakamura, Abstracts of papers, the Annual Meeting of the Agricultural Chemical Society of Japan, Yokohama, April, p. 343 (1977). 